\title{
Elevated neutrophil-to-lymphocyte ratio is an independent poor prognostic factor in patients with intrahepatic cholangiocarcinoma
}

\author{
Guohe Lin ${ }^{1,2, *}$, Yongcheng Liu ${ }^{1,4, *}$, Shuhong Li ${ }^{1,2,5, *}$, Yize Mao ${ }^{1,2,3}$, Jun Wang ${ }^{1,2,3}$, Zeyu \\ Shuang ${ }^{1,2,3}$, Jianlin Chen ${ }^{1,2,3}$ and Shengping $\mathbf{L i}^{1,2,3}$ \\ ${ }^{1}$ State Key Laboratory of Oncology in South China, Cancer Center, Sun Yat-sen University, Guangzhou, China \\ 2 National Collaborative Innovation Center for Cancer Medicine, Guangzhou, China \\ ${ }^{3}$ Department of Hepatobiliary Oncology, Sun-Yat-sen University Cancer Center, Guangzhou, China \\ ${ }^{4}$ Department of Surgical Oncology, Sir Run Run Shaw Hospital, Zhejiang University School of Medicine, Hangzhou, China \\ ${ }^{5}$ Department of Endoscopy, Sun Yat-sen University Cancer Center, Guangzhou, China \\ * These authors have contributed equally to this work \\ Correspondence to: Shengping Li, email: lishp@sysucc.org.cn \\ Keywords: intrahepatic cholangiocarcinoma, neutrophil-to-lymphocyte ratio, CD4+ T cells, CD8+ T cells, prognosis \\ Received: July 23, $2015 \quad$ Accepted: February 13, $2016 \quad$ Published: February 24, 2016
}

\section{ABSTRACT}

We investigated whether elevated neutrophil-to-lymphocyte ratio ( NLR ) was associated with poor anti-tumor immunity and prognosis in patients with intrahepatic cholangiocarcinoma ( ICC ). Clinicopathologic data of 102 patients with ICC who underwent hepatectomy was retrospectively analyzed. The Kaplan-Meier method and Cox regression model were used to analyze the survival and prognosis. The percentage of overall lymphocytes, $T$ cells and CD8 $+T$ cells in the high NLR group was lower than that in the low NLR group. The percentage of PD-1+CD4+ and PD$1+C D 8+T$ cells was higher and the percentage of IFN- $Y+C D 4+$ and IFN- $y+C D 8+T$ cells was lower in the high NLR group than that in the low NLR group ( $p=0.045$, $p=0.008 ; p=0.012, p=0.006$ ). Density of tumor-infiltrating CD3 $+\mathrm{T}$ cells in the high NLR group was lower than that in the low NLR group $(p<0.001)$. Elevated NLR was an independent predictor for poor overall survival ( OS; $p=0.035$ ) and recurrence-free survival ( $R F S ; p=0.008$ ). These results indicate that elevated NLR is associated with poor anti-tumor immunity and could be a poor biomarker for prognosis in patients with ICC.

\section{INTRODUCTION}

Intrahepatic cholangiocarcinoma ( ICC ) and hepatocellular carcinoma ( $\mathrm{HCC}$ ) are the most common primary liver tumors, but ICC is a fatal malignancy which arises from the epithelium of intrahepatic bile duct [1]. Currently, surgical resection remains the only effective treatment for early stage ICC, but most patients lose the chances because effective methods for diagnosis of the disease in early stage are lacking [2]. Adjuvant chemotherapy and radiotherapy have shown limited effects for patients with ICC because of insensitivity to chemotherapeutics and resistance to radiotherapy [3-4]. The 5 years survival rate of patients with ICC is only $2.6 \%$ [5].
The inflammatory response seems to contribute to the occurrence and development of numerous cancers [6]. Patients with primary sclerosing cholangitis characterized by chronic biliary inflammation have a high risk of developing to biliary tract cancers [7]. However, immune cells such as lymphocytes can contribute to or inhibit the development of tumors depending on the cytokines or effective molecules in the tumor microenvironment $[8,9]$. CD8 $+\mathrm{T}$ cells play a vital role in preventing the development of tumors. However, PD-1 expression on $\mathrm{CD} 8+\mathrm{T}$ cells is upregulated in patients with $\mathrm{HCC}$ and activation of PD-1 is an important mechanism by which tumor cells can inhibit anti-tumor immune responses mediated by CD8 $+\mathrm{T}$ cells $[10,11]$. Thus, both the inflammatory response and immune response participate in the process of tumor development. 
Several studies have shown that a high NLR is a prognostic factor for poor OS and RFS in many types of cancers, including colorectal cancer and diffuse large B-cell lymphoma $[12,13]$. Recently, studies have shown that NLR reflects the balance between the inflammatory response and the immune response, but these studies did not analyze the relationship between NLR and anti-tumor immunity $[14,15]$. Our study was designed to evaluate whether elevated NLR was associated with poor antitumor immunity and was a poor biomarker for OS and RFS in patients with ICC.

\section{RESULTS}

\section{The clinic and pathologic features of ICC patients with high and low NLR}

The patients with ICC were divided into high NLR group ( $n=43$ ) and the low NLR group ( $n=59$ ) according to the cutoff of 3 . There were no statistic differences between high and low NLR patients in age, gender, lymph node metastases, liver cirrhosis, distant metastases, tumor differentiation or tumor number ( Table 1 ). Elevated NLR was associated with elevated plasmic CEA ( $p=0.033$; Table 1$)$. Tumor size in the high NLR group was significantly larger than that in the low NLR group ( $p=0.024$; Table 1 ). Moreover, NLR increased progressively through early TNM stage to advanced TNM stage ( $p=0.015$; Table 1$)$. Our results indicated that elevated NLR was associated with the development and progression of ICC.

\section{Elevated NLR was an independent prognostic factor for poor overall survival}

The OS of the patients in the high NLR group was significantly shorter than that in the low NLR group ( $p=$ 0.009; Figure 2A ). Univariate analysis identified lymph node metastases $(p<0.001)$, tumor number $\geq 2(p=$ $0.002)$, tumor size $\geq 5 \mathrm{~cm}(p=0.006)$, advanced TNM stage $(p<0.001)$ and NLR $\geq 3(p=0.010)$ as significant prognostic factors for poor OS ( Table 2 ). Multivariate analysis identified lymph node metastases ( $p=0.011$ ) and NLR $\geq 3(p=0.035)$ as independent prognostic factors for poor OS ( Table 2 ).

\section{Elevated NLR was an independent prognostic factor for poor recurrence-free survival}

The RFS in the high NLR group was significantly shorter than that in the low NLR group ( $p=0.015$; Figure $2 \mathrm{~B})$. Univariate analysis identified tumor number $\geq 2$ ( $p=0.004)$, liver cirrhosis $(p=0.030)$, AFP $\geq 25 \mathrm{ng} /$ $\mathrm{ml}(p=0.002)$ and NLR $\geq 3(p=0.017)$ as significant prognostic factors for poor RFS ( Table 3 ). Multivariate analysis identified tumor number $\geq 2(p=0.001)$, liver cirrhosis $(p=0.045), \mathrm{AFP} \geq 25 \mathrm{ng} / \mathrm{ml}(P=0.005)$ and NLR $\geq 3(p=0.008)$ as independent prognostic factors for poor RFS ( Table 3 ).

\section{Elevated NLR was associated with poor anti- tumor immunity}

The percentage of overall lymphocytes to leukocytes in the high NLR group was lower than that in the low NLR group ( $15.59 \pm 4.60 v s .28 .44 \pm 5.20, p<0.001$; Figure 1A ). Furthermore, we found that the percentage of $\mathrm{T}$ cells and CD8 $+\mathrm{T}$ cells to total lymphocytes in the high NLR group was lower than that in the low NLR group ( $62.33 \pm 8.36$ vs. $72.73 \pm 5.50, p=0.018 ; 17.51 \pm 4.11 v s$. $29.26 \pm 7.18, p=0.006, n=7$; Figure 1B ). There were no significant differences in the percentage of CD4+ T cells and B cells to total lymphocytes between the high NLR group and the low NLR group ( $38.20 \pm 4.38 v s .37 .90 \pm$ 8.32, $p=0.934 ; 4.71 \pm 1.31$ vs. $8.49 \pm 5.71, p=0.113, n$ $=7$; Figure 1B ). The percentage of PD-1+CD4+ and PD$1+\mathrm{CD} 8+\mathrm{T}$ cells in the high NLR group was higher than that in the low NLR group ( $10.92 \pm 7.56$ vs. $2.88 \pm 0.63$, $p=0.045 ; 18.90 \pm 8.04$ vs. $5.28 \pm 3.54, p=0.008, n=5$; Figure 1C, 1D ). Compared with the low NLR group, the percentage of IFN- $\gamma+\mathrm{CD} 4+$ and IFN $-\gamma+\mathrm{CD} 8+\mathrm{T}$ cells was lower in the high NLR group ( $7.30 \pm 4.31$ vs. $15.92 \pm$ $4.13, p=0.012 ; 15.16 \pm 7.01 v s .31 .22 \pm 6.87, p=0.006$, $n=5$; Figure $1 \mathrm{E}, 1 \mathrm{~F}$ ). The density of tumor-infiltrating CD3 + T cells in the high NLR group was lower than that in the low NLR group ( $15 \pm 14 v s .43 \pm 30$ cells/field, $p$ $<0.001, n=20$; Figure $1 \mathrm{G}, 1 \mathrm{H})$. Our results indicated that elevated NLR was associated with poor anti-tumor immunity.

\section{DISCUSSION}

Excessive inflammation contributes to the development of tumor cells [16]. Neutrophils contribute to the process of inflammation by activating proangiogenic factors including vascular endothelial growth factor or inflammatory cytokines including IL-1 $\beta$ [17-18]. Elevated neutrophil levels are associated with decreased OS in advanced non-small-cell lung cancer [19]. Poor antitumor immunity in the tumor microenvironment is another important factor for tumor progression. Lymphocytes are crucial components of innate immunity and the adaptive immune response, and can eradicate tumor cells by cytotoxic cell death and cytokine secretion [10]. Some evidence shows that a low lymphocyte count could be responsible for a weakened defense against cancers [20]. A low density of CD8+ T cells in tumor tissues is associated with poor prognosis in patients with hepatocellular cancer 

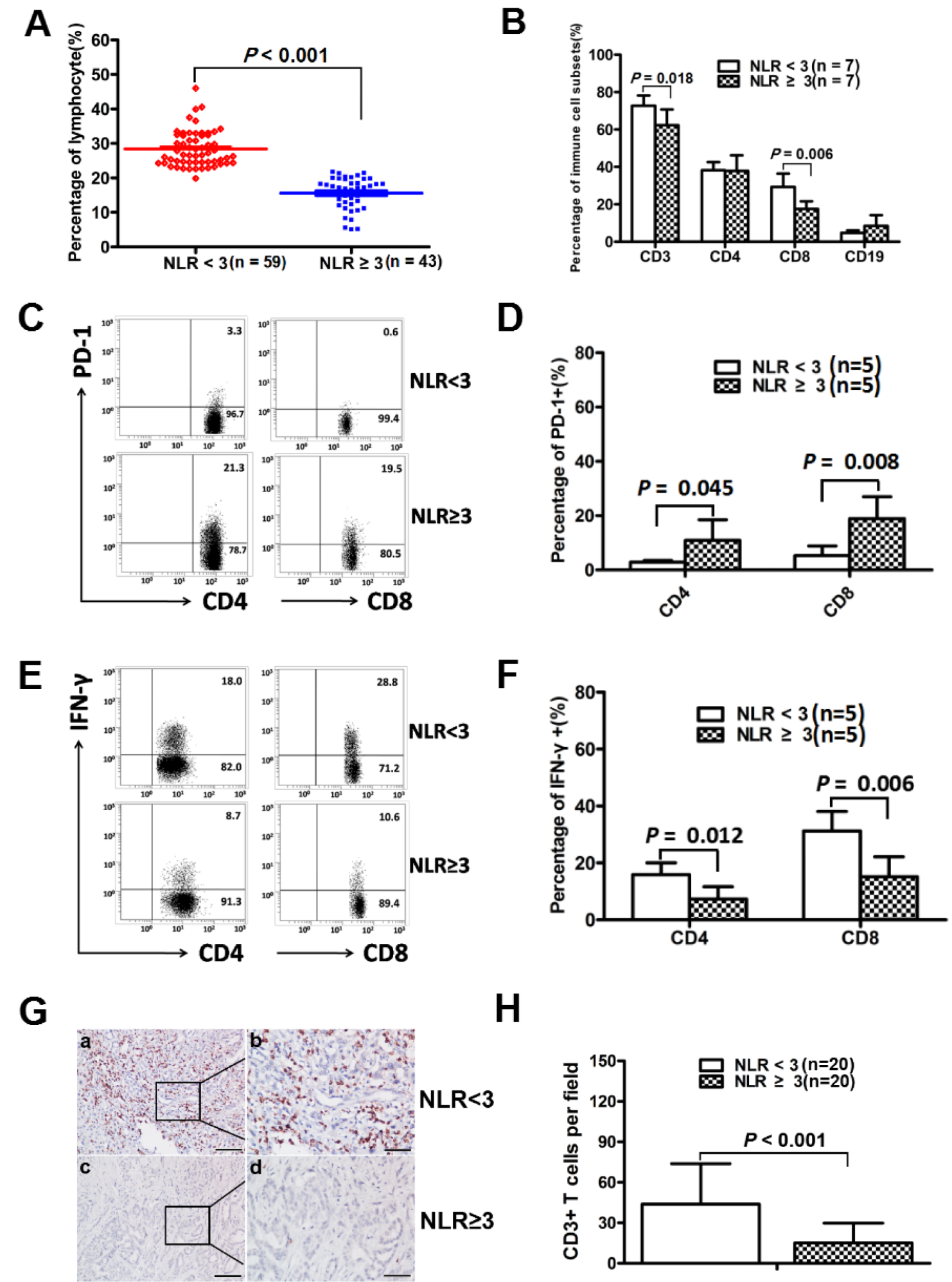

H

Figure 1: Elevated NLR was associated with poor anti-tumor immunity. A. The percentage of overall lymphocytes to leukocytes in the high NLR group was significantly lower than that in the low NLR group $(p<0.001)$. B. The percentage of T cells and CD8+ T cells to total lymphocytes in the high NLR group was significantly lower than that in the low NLR group $(p=0.018 ; p=0.006)$. C., D. The percentage of PD-1+CD4+ and PD-1+CD8+ T cells in the high NLR group were higher than that in the low NLR group $(p=0.045, p=0.008, n=5)$. E., F. The percentage of IFN $-\gamma+\mathrm{CD} 4+$ and IFN $-\gamma+\mathrm{CD} 8+\mathrm{T}$ cells in the high NLR group were lower than in the low NLR group $(p=0.012, p$ $=0.006, n=5)$. G. Representative immunohistochemistry images of CD3 in intratumoral regions. Scale bar, $100 \mu \mathrm{m}(\mathrm{a}, \mathrm{c}), 50 \mu \mathrm{m}(\mathrm{b}, \mathrm{d}$ ). H. The numbers of CD3+ T cells in the high NLR group and in the low NLR group. Cell numbers were calculated as the cell count per $\times 400$ field. 
Table 1: The correlation between NLR and clinicopathological characteristics in patients with ICC

\begin{tabular}{|c|c|c|c|}
\hline Factors & NLR $<3$ & $\mathbf{N L R} \geq 3$ & $P$ \\
\hline \multicolumn{4}{|l|}{ Gender } \\
\hline Male & 34 & 32 & \\
\hline Female & 25 & 11 & 0.0611 \\
\hline \multicolumn{4}{|c|}{ Age (years) } \\
\hline$\leq 50$ & 20 & 15 & \\
\hline$>50$ & 39 & 28 & 0.541 \\
\hline \multicolumn{4}{|c|}{ CA19-9 (U/ml) } \\
\hline$<35$ & 27 & 15 & \\
\hline$\geq 35$ & 32 & 28 & 0.185 \\
\hline \multicolumn{4}{|c|}{ CEA (ng/ml) } \\
\hline$<5$ & 49 & 28 & \\
\hline$\geq 5$ & 10 & 15 & 0.033 \\
\hline \multicolumn{4}{|c|}{ LDH (U/ml) } \\
\hline$<206$ & 33 & 30 & \\
\hline$\geq 206$ & 26 & 13 & 0.112 \\
\hline \multicolumn{4}{|c|}{ GGT (U/ml) } \\
\hline$<46.3$ & 8 & 8 & \\
\hline$\geq 46.3$ & 51 & 35 & 0.336 \\
\hline \multicolumn{4}{|c|}{$\operatorname{AFP}(\mathrm{ng} / \mathrm{ml})$} \\
\hline$<25$ & 54 & 40 & \\
\hline$\geq 25$ & 5 & 3 & 0.544 \\
\hline \multicolumn{4}{|c|}{ Lymph node metastases } \\
\hline Yes & 16 & 16 & \\
\hline No & 43 & 27 & 0.192 \\
\hline \multicolumn{4}{|c|}{ Tumor size (cm) } \\
\hline$\leq 5$ & 32 & 14 & \\
\hline$>5$ & 27 & 29 & 0.024 \\
\hline \multicolumn{4}{|c|}{ Tumor number } \\
\hline Single & 44 & 28 & \\
\hline Multiple & 15 & 15 & 0.207 \\
\hline \multicolumn{4}{|c|}{ Distant metastases } \\
\hline Yes & 3 & 6 & \\
\hline No & 56 & 37 & 0.115 \\
\hline \multicolumn{4}{|c|}{ Tumor differentiation } \\
\hline $\mathrm{I}-\mathrm{II}$ & 27 & 19 & \\
\hline III-IV & 32 & 24 & 0.518 \\
\hline \multicolumn{4}{|c|}{ Liver cirrhosis } \\
\hline Yes & 17 & 12 & \\
\hline No & 42 & 31 & 0.550 \\
\hline \multicolumn{4}{|c|}{ TNM staging } \\
\hline I-II & 36 & 16 & \\
\hline III-IV & 23 & 27 & 0.015 \\
\hline
\end{tabular}


Table 2: Univariate and multivariate analysis of the associations between prognostic variables and overall survival in patients with ICC

\begin{tabular}{|c|c|c|c|c|c|c|}
\hline \multirow[b]{2}{*}{ Variables } & \multicolumn{3}{|c|}{ Univariate } & \multicolumn{3}{|c|}{ Multivariate } \\
\hline & HR & $95 \% \mathrm{CI}$ & $\boldsymbol{P}$ & HR & $95 \% \mathrm{CI}$ & $\boldsymbol{P}$ \\
\hline Age (years, $>50 v s . \leq 50)$ & 1.217 & $0.707-2.097$ & 0.478 & & & \\
\hline Gender (female $v s$. male ) & 0.760 & $0.441-1.308$ & 0.321 & & & \\
\hline CA 19-9 $(\mathrm{U} / \mathrm{ml}, \geq 35$ vs. $<35)$ & 1.147 & $0.687-1.914$ & 0.601 & & & \\
\hline $\mathbf{C E A}(\mathrm{ng} / \mathrm{ml}, \geq 5 v s .<5)$ & 1.076 & $0.600-1.933$ & 0.600 & & & \\
\hline LDH $(\mathrm{U} / \mathrm{ml}, \geq 206 v s .<206)$ & 1.217 & $0.734-2.018$ & 0.447 & & & \\
\hline GGT $(\mathrm{U} / \mathrm{ml}, \geq 46.3$ vs. $<46.3)$ & 1.711 & $0.775-3.777$ & 0.183 & & & \\
\hline $\mathbf{A F P}(\mathrm{ng} / \mathrm{ml}, \geq 25 v s .<25)$ & 1.528 & $0.657-3.556$ & 0.325 & & & \\
\hline Lymph node metastases (yes $v s$. no) & 2.854 & $1.711-4.759$ & $<0.001$ & 2.103 & $1.182-3.741$ & 0.011 \\
\hline Tumor size $(\mathrm{cm}, \geq 5$ vs. $<5)$ & 2.086 & $1.239-3.512$ & 0.006 & 1.385 & $0.793-2.420$ & 0.252 \\
\hline Tumor number (multiple $v s$. single) & 2.274 & $1.356-3.813$ & 0.002 & 1.641 & $0.937-2.875$ & 0.083 \\
\hline Distant metastases (yes vs. no) & 1.853 & $0.880-3.902$ & 0.104 & & & \\
\hline $\begin{array}{l}\text { Tumor differentiation (I-II vs.III- } \\
\text { IV) }\end{array}$ & 1.272 & $0.763-2.121$ & 0.357 & & & \\
\hline Liver cirrhosis (yes vs. no) & 1.621 & $0.953-2.756$ & 0.075 & & & \\
\hline TNM stage (I-II vs.III-IV) & 3.104 & $1.821-5.293$ & $<\mathbf{0 . 0 0 1}$ & 1.765 & $0.923-3.374$ & 0.086 \\
\hline $\operatorname{NLR}(\geq 3 v s .<3)$ & 1.951 & $1.174-3.242$ & 0.010 & 1.756 & $1.040-2.963$ & $\mathbf{0 . 0 3 5}$ \\
\hline
\end{tabular}

Abbreviations: CEA, carcino-embryonicantigen; CA19-9, carbohydrate antigen 19-9, HR, hazard ratio; CI, confidence interval.
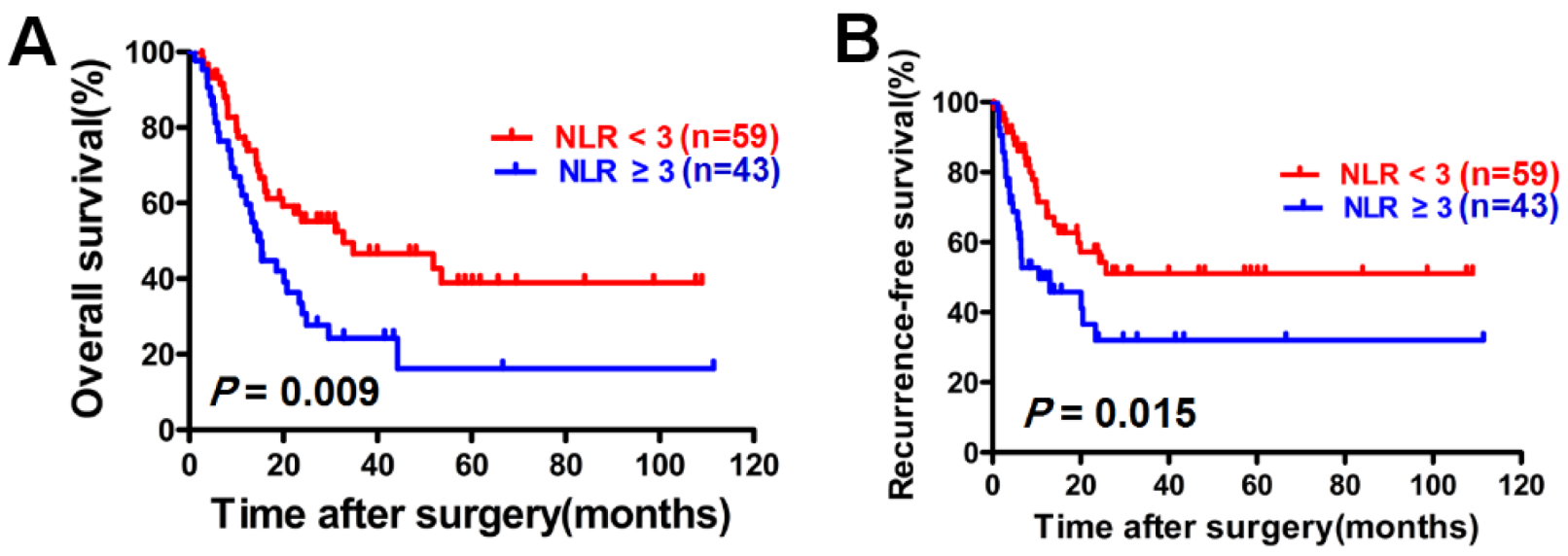

Figure 2: Elevated NLR correlates with a poor prognosis in patients with ICC. The patients with ICC were divided into high NLR group ( $n=43$ ) and the low NLR group ( $n=59$ ) according to the cutoff of 3. Kaplan-Meier analysis was conducted to disclose the relationship of NLR with the overall survival A. and recurrence-free survival B. ( log-rank test ).

$[21,22]$. In addition, peripheral blood neutrophils suppress the cytolytic activity of lymphocytes and natural killer cells to tumor cells in vitro [23].

The dysfunction of CD8 $+\mathrm{T}$ cells is an important factor for poor anti-tumor immunity in tumor progression. Some underlying mechanisms for this dysfunction are attributed to increased levels of immunosuppressive cytokines or molecules such as TGF- $\beta$, PD- 1 and Tim3 [24-27]. Recent researches indicate that NLR reflects the balance between the inflammatory response and the immune response, but these studies do not analyze impaired immune cell subsets or the potential mechanisms $[14,15]$. We found that elevated NLR was associated with poor anti-tumor immunity in patients with ICC. First, the percentage of overall lymphocytes to leukocytes in the high NLR group was lower than that in the low NLR group. Second, the percentage of T cells and CD8+ $\mathrm{T}$ cells to total lymphocytes in high NLR group was lower than that in the low NLR group. Third, we found that the percentage of PD- $1+\mathrm{CD} 4+$ and $\mathrm{PD}-1+\mathrm{CD} 8+\mathrm{T}$ cells was higher and the percentage of IFN- $\gamma+\mathrm{CD} 4+$ and IFN $-\gamma+$ CD8 + T cells was lower in the high NLR group than that in the low NLR group. The results indicated that elevated NLR was associated with increased PD-1 expression and decreased IFN- $\gamma$ secretion. Last, elevated NLR was associated with reduced tumor-infiltrating 
Table 3: Univariate and multivariate analysis of the associations between prognostic variables and recurrence-free survival in patients with ICC

\begin{tabular}{|c|c|c|c|c|c|c|}
\hline \multirow[b]{2}{*}{ Variables } & \multicolumn{3}{|c|}{ Univariate } & \multicolumn{3}{|c|}{ Multivariate } \\
\hline & HR & $95 \% \mathrm{CI}$ & $P$ & HR & $95 \% \mathrm{CI}$ & $P$ \\
\hline Age (years, $>50$ vs. $\leq 50)$ & 1.039 & $0.569-1.902$ & 0.901 & & & \\
\hline Gender (female vs. male ) & 0.630 & $0.340-1.165$ & 0.141 & & & \\
\hline CA 19-9 (U/ml, $\geq 35$ vs. < 35) & 0.835 & $0.471-1.482$ & 0.539 & & & \\
\hline CEA $(\mathrm{ng} / \mathrm{ml}, \geq 5 v s .<5)$ & 1.745 & $0.932-3.267$ & 0.082 & & & \\
\hline LDH $(\mathrm{U} / \mathrm{ml}, \geq 206 v s .<206)$ & 1.089 & $0.607-1.953$ & 0.774 & & & \\
\hline GGT (U/ml, $\geq 46.3 v s .<46.3)$ & 1.201 & $0.537-2.687$ & 0.656 & & & \\
\hline $\mathbf{A F P}(\mathrm{ng} / \mathrm{ml}, \geq 25 v s .<25)$ & 3.655 & $1.628-8.208$ & 0.002 & 3.713 & $1.502-9.181$ & 0.005 \\
\hline Lymph node metastases (yes vs. no) & 1.285 & $0.672-2.457$ & 0.449 & & & \\
\hline Tumor size $(\mathrm{cm}, \geq 5 v s .<5)$ & 1.725 & $0.962-3.091$ & 0.067 & & & \\
\hline Tumor number (multiple vs. single) & 2.406 & $1.329-4.356$ & 0.004 & 2.782 & $1.494-5.182$ & 0.001 \\
\hline Distant metastases (yes $v s$. no) & 1.697 & $0.670-4.299$ & 0.265 & & & \\
\hline Tumor differentiation (I-II vs.III-IV) & 1.617 & $0.892-2.932$ & 0.114 & & & \\
\hline Liver cirrhosis (yes vs. no) & 1.966 & $1.068-3.618$ & $\mathbf{0 . 0 3 0}$ & 2.016 & $1.017-3.997$ & 0.045 \\
\hline TNM stage (I-II vs.III-IV) & 1.515 & $0.848-2.707$ & 0.160 & & & \\
\hline $\operatorname{NLR}(\geq 3 v s .<3)$ & 2.009 & $1.131-3.571$ & $\mathbf{0 . 0 1 7}$ & 2.260 & $1.242-4.114$ & 0.008 \\
\hline
\end{tabular}

Abbreviations: CEA, carcino-embryonicantigen; CA19-9, carbohydrate antigen 19-9, HR, hazard ratio; CI, confidence interval.

$\mathrm{CD} 3+\mathrm{T}$ cells in tumor tissue. Our results indicate that the poor prognosis in high NLR group could be ascribed to an excessive inflammatory response and poor anti-tumor immunity response.

Recently, increasing evidence has shown that elevated NLR is associated with poor clinical outcome in patients with various cancers [28-30]. Chen et al. showed that elevated NLR predicted a poor prognosis in patients with intrahepatic cholangiocarcinoma who underwent hepatectomy [31]. These findings are in line with our results. In our study, the optimal cutoff of 3 was used for NLR because of its convenience and powerful prognostic value $[32,33]$. We found that elevated NLR was associated with decreased OS and RFS. Our results show that NLR $\geq 3$ is an independent predictor for poor OS and RFS, which indicates that elevated NLR could be a convenient biomarker to identify patients with a poor prognosis after liver resection.

There were some limitations in this study. First, this was a retrospective analysis from a single center. Second, we did not analyze preoperative $\mathrm{C}$ reactive protein (CRP) change together with NLR because it is not routinely measured in our daily practice. Third, immunosuppressive cells such as regulatory $\mathrm{T}$ cell (Treg) were not included in this study. Treg can contribute to the development of cancer by inhibiting the proliferation of $\mathrm{T}$ cells and secreting suppressive cytokines [34-36].

In conclusion, our study demonstrates that elevated NLR is associated with poor anti-tumor immunity and could be used to identify patients with a poor prognosis. Elevated NLR is a poor biomarker for OS and RFS in patients with ICC after hepatectomy.

\section{MATERIALS AND METHODS}

\section{Patients and tissue specimens}

102 consecutive patients were diagnosed with ICC and received liver resection in the Department of Hepatobiliary Surgery at the Cancer Center of Sun Yat-sen University ( Guangzhou, China ) between November 1999 and November 2011. None of patients underwent preoperative therapies such as radiotherapy or chemotherapy. Neutrophil and lymphocyte counts were obtained 1 week before histologically proven diagnosis. NLR was calculated by dividing the absolute neutrophil count by the absolute lymphocyte count. Applying receiver operating characteristic( ROC ) curve, the cutoff for the NLR was 2.96 , but 3 was used for the optimal cutoff for the NLR because of its convenience and powerful prognostic value ( NLR $<3$, NLR $\geq 3$ ) $[32,33]$. Followup of patients was performed every three months in the first 3 years and 6 months thereafter. OS was defined as the interval between surgery and death or between surgery and the last observation for surviving patients. RFS was defined as the interval between surgery and recurrence or between surgery and the last observation for patients without recurrence. The research was approved by the institutional review board of Sun Yat-sen University Cancer Center, and written informed consent was obtained 
from each patient involved in the study.

\section{Immunohistochemistry}

5- $\mu \mathrm{m}$ thick formalin-fixed and paraffin-embedded samples were processed for immunohistochemistry stainning with antibodies against human CD3 ( 1:500 dilution, Dako A/S, Glostrup, Copenhagen, Denmark ) or control antibodies ( Santa Cruz Biotechnology, Santa Cruz, CA, USA). The density of CD3+ were evaluated quantitatively by the mean number at five representative fields at $400 \times$ magnification by two independent observers who were blinded to the clinical outcome. A significant linear correlation existed between the counts of two independent observers and the average counts of the two investigators was used in subsequent analyses to minimize inter-observer variability.

\section{Flow cytometry analysis}

Peripheral blood mononuclear cells ( PBMCs ) were isolated from fresh heparinized blood by Ficoll density gradient centrifugation. For phenotypic analysis, the cells were washed twice and stained for $30 \mathrm{~min}$ on ice with mixtures of fluorescence-conjugated surface mAbs or isotype-matched controls, and the cells were then washed twice and resuspended in PBS buffer for flow cytometry analysis. PBMCs were stained with the following antibodies: phycoertthrin-cyanin 5 ( PE-Cy5 )-conjugated anti-CD3 ( eBioscience, San Diego, CA, USA ); fluorescein isothiocyanate ( FITC )-conjugated anti-CD4, anti-CD8 and anti-CD19 ( eBioscience ); phycoertthrin-cyanin 7 ( PE-Cy7 )-conjugated anti-CD4 ( eBioscience ); PE-conjugated anti-PD-1 ( eBioscience ) and anti-IFN- $\gamma$ ( eBioscience ).

\section{Statistical analysis}

The optimal cutoff value for NLR was determined using time-dependent ROC curve analysis, which was performed using $\mathrm{R}$ software, version 3.2.2. ( The $\mathrm{R}$ foundation for statistical computing, Vienna, Austria. http://www.r-pro-ject.org ) and the 'survival ROC' package. Statistical analysis was performed using SPSS 13.0 statistical software. The differences in numerical data between the two groups were compared by Student $t$ tests. Categorical variables were compared using the $\chi^{2}$-tests. The Kaplan-Meier method and Cox regression model were used to analyze survival and prognosis. All statistical tests were two-sided, and a significant difference was considered when $p<0.05$.

\section{CONFLICTS OF INTEREST}

No potential conflicts of interest were disclosed.

\section{GRANT SUPPORT}

This work was supported by the National Natural Science Foundation of China ( Grant No.81171890); Guangdong Province Natural Scientific Foundation ( Grant No.S2011010004047 ); and the National Basic Research Program of China ( 973, No.2013CB910304 ).

\section{REFERENCES}

1. Altekruse SF, Petrick JL, Cuccinelli JE, Zou Z, Tatalovich Z, McGlynn KA. Geographic variation of intrahepatic cholangiocarcinoma, extrahepatic cholangiocarcinoma, and hepatocellular carcinoma in the United States. PLoS one. 2015; 10:e0120574. doi: 10.1371/journal.pone.0120574.

2. Amini N, Ejaz A, Spolverato G, Kim Y, Herman JM and Pawlik TM. Temporal trends in liver-directed therapy of patients with intrahepatic cholangiocarcinoma in the United States: a population-based analysis. Journal of surgical oncology. 2014; 110:163-170.

3. Dhanasekaran R, Hemming AW, Zendejas I, George T, Nelson DR, Soldevila-Pico C, Firpi RJ, Morelli G, Clark V and Cabrera R. Treatment outcomes and prognostic factors of intrahepatic cholangiocarcinoma. Oncology reports. 2013; 29:1259-1267.

4. Ibarra RA, Rojas D, Snyder L, Yao M, Fabien J, Milano M, Katz A, Goodman K, Stephans K, El-Gazzaz G, Aucejo F, Miller C, Fung J, Lo S, Machtay M and Sanabria JR. Multicenter results of stereotactic body radiotherapy (SBRT) for non-resectable primary liver tumors. Acta oncologica. 2012; 51:575-583.

5. Shaib YH, Davila JA, McGlynn K, EI-Serag HB. Rising incidence of intrahepatic cholangiocarcinoma in the United States: a true increase? Journal of Hepatology. 2004; 40:472-477.

6. Coussens LM and Werb Z. Inflammation and cancer. Nature. 2002; 420:860-867.

7. Ishii Y, Sasaki T, Serikawa M, Minami T, Okazaki A, Yukutake M, Ishigaki T, Kosaka K, Mouri T, Yoshimi S, Shimizu A, Tsuboi T and Chayama K. Elevated expression of cyclooxygenase-2 and microsomal prostaglandin E synthase-1 in primary sclerosing cholangitis: iotamplications for cholangiocarcinogenesis. International journal of oncology. 2013; 43:1073-1079.

8. Kim HJ and Cantor H. CD4 T-cell subsets and tumor immunity: the helpful and the not-so-helpful. Cancer immunology research. 2014; 2:91-98.

9. Steer HJ, Lake RA, Nowak AK and Robinson BW. Harnessing the immune response to treat cancer. Oncogene. 2010; 29:6301-6313. 
10. Shi F, Shi M, Zeng Z, Qi RZ, Liu ZW, Zhang JY, Yang YP, Tien P and Wang FS. PD-1 and PD-L1 upregulation promotes CD8+T-cell apoptosis and postoperative recurrence in hepatocellular carcinoma patients. International Journal of Cancer. 2010; 128:887-896.

11. Topalian SL, Drake CG and Pardoll DM. Immune checkpoint blockade: a common denominator approach to cancer therapy. Cancer Cell. 2015; 27:450-461.

12. Absenger G, Szkandera J, Pichler M, Stotz M, Arminger F, Weissmueller M, Schaberl-Moser R, Samonigg H, Stojakovic T and Gerger A. A derived neutrophil to lymphocyte ratio predicts clinical outcome in stage II and III colon cancer patients. British journal of cancer. 2013; 109:395-400.

13. Troppan K, Deutsch A, Gerger A, Stojakovic T, BehamSchmid C, Wenzl K, Neumeister P and Pichler M. The derived neutrophil to lymphocyte ratio is an independent prognostic factor in patients with diffuse large B-cell lymphoma. British journal of cancer. 2014; 110:369-374.

14. Dan JQ, Zhang YJ, Peng ZW, Huang JT, Gao HJ, Xu L and Chen MS. Postoperative neutrophil-to-lymphocyte ratio change predicts survival of patients with small hepatoceellular caarcinoma undergoing radiofrequency ablation. Plos one. 2013; 8(3).

15. Cho H, Hur HW, Kim SW, Kim SH, Kim JH, Kim YT and Lee K. Pre-treatment neutrophil to lymphocyte ratio is elevated in epithelial ovarian cancer and predicts survival after treatment. Cancer immunologyimmunotherapy. 2009; 58:15-23.

16. Mantovani A, Allavena P, Sica A and Balkwill F. Cancerrelated inflammation. Nature. 2008; 454:436-444.

17. Nozawa H, Chiu C and Hanahan D. Infiltrating neutrophils mediate the initial angiogenic switch in a mouse model of multistage carcinogenesis. Proceedings of the National Academy of Sciences of the United States of America. 2006; 103:12493-1298.

18. Croker BA, Lewis RS, Babon JJ, Mintern JD, Jenne DE, Metcalf D, Zhang JG, Cengia LH, O'Donnell JA and Roberts AW. Neutrophils require SHP1 to regulate IL-1beta production and prevent inflammatory skin disease. Journal of immunology. 2011; 186:1131-1139.

19. Teramukai S, Kitano T, Kishida Y, Kawahara M, Kubota K, Komuta K, Minato K, Mio T, Fujita Y, Yonei T, Nakano K, Tsuboi M, Shibata K, Furuse K and Fukushima M. Pretreatment neutrophil count as an independent prognostic factor in advanced non-small-cell lung cancer: an analysis of Japan Multinational Trial Organisation LC00-03. European journal of cancer. 2009; 45:1950-1958.

20. Liu S, Lachapelle J, Leung S, Gao D, Foulkes WD and Nielsen TO. CD8+ lymphocyte infiltration is an independent favorable prognostic indicator in basal-like breast cancer. Breast cancer research. 2012; 14:R48.

21. Murphy KA, Erickson JR, Johnson CS, Seiler CE, Bedi J, Hu P, Pluhar GE, Epstein AL and Ohlfest JR. CD8+ T cell- independent tumor regression induced by Fc-OX40L and therapeutic vaccination in a mouse model of glioma. Journal of immunology. 2014; 192:224-233.

22. Nedergaard BS, Ladekarl M, Thomsen HF, Nyengaard JR and Nielsen K. Low density of CD3+, CD4+ and $\mathrm{CD} 8+$ cells is associated with increased risk of relapse in squamous cell cervical cancer. British journal of cancer. 2007; 97:1135-1138.

23. Fridlender ZG, Sun J, Kim S, Kapoor V, Cheng G, Ling L, Worthen GS and Albelda SM. Polarization of tumorassociated neutrophil phenotype by TGF-beta: "N1" versus “N2" TAN. Cancer cell. 2009; 16:183-194.

24. Hoffman BE, Martino AT, Sack BK, Cao O, Liao G, Terhorst $\mathrm{C}$ and Herzog RW. Nonredundant roles of IL10 and TGF-beta in suppression of immune responses to hepatic AAV-factor IX gene transfer. Molecular therapy. 2011; 19:1263-1272.

25. Erickson JJ, Rogers MC, Hastings AK, Tollefson SJ and Williams JV. Programmed death-1 impairs secondary effector lung $\mathrm{CD} 8(+) \mathrm{T}$ cells during respiratory virus reinfection. Journal of immunology. 2014; 193:5108-5117.

26. Sharon E, Streicher H, Goncalves P and Chen HX. Immune checkpoints in cancer clinical trials. Chin J cancer. 2014; 33:434-444.

27. Cho JL, Roche MI, Sandall B, Brass AL, Seed B, Xavier RJ and Medoff BD. Enhanced Tim3 activity improves survival after influenza infection. Journal of immunology. 2012; 189:2879-2889.

28. Szkandera J, Absenger G, Liegl-Atzwanger B, Pichler M, Stotz M, Samonigg H, Glehr M, Zacherl M, Stojakovic T, Gerger A and Leithner A. Elevated preoperative neutrophil/ lymphocyte ratio is associated with poor prognosis in softtissue sarcoma patients. British journal of cancer. 2013; 108:1677-1683.

29. Sharaiha RZ, Halazun KJ, Mirza F, Port JL, Lee PC, Neugut AI, Altorki NK and Abrams JA. Elevated preoperative neutrophil:lymphocyte ratio as a predictor of postoperative disease recurrence in esophageal cancer. Annals of surgical oncology. 2011; 18:3362-3369.

30. Shimada H, Takiguchi N, Kainuma O, Soda H, Ikeda A, Cho A, Miyazaki A, Gunji H, Yamamoto H and Nagata M. High preoperative neutrophil-lymphocyte ratio predicts poor survival in patients with gastric cancer. Gastric cancer . 2010; 13:170-176.

31. Chen Q, Yang LX, Li XD, Yin D, Shi SM, Chen EB, Yu L, Zhou ZJ, Zhou SL, Shi YH, Fan J, Zhou J and Dai Z. The elevated preoperative neutrophil-to-lymphocyte ratio predicts poor prognosis in intrahepatic cholangiocarcinoma patients undergoing hepatectomy. Tumour biology .2015.

32. SI, Lee A, Lee US, Choi HJ, Kang MH, Kang JH, Jeon KN, Park MJ, Kim SH and Lee GW. Clinical significance of the neutrophil-lymphocyte ratio in venous thromboembolism patients with lung cancer. Lung cancer. 2014; 84:79-85.

33. Rossi L, Santoni M, Crabb SJ, Scarpi E, Burattini L, Chau 
C, Bianchi E, Savini A, Burgio SL, Conti A, Conteduca V, Cascinu S and De Giorgi U. High neutrophil-to-lymphocyte ratio persistent during first-line chemotherapy predicts poor clinical outcome in patients with advanced urothelial cancer. Annals of surgical oncology. 2015; 22:1377-1384.

34. Winstead CJ, Fraser JM and Khoruts A. Regulatory CD4+CD25+Foxp3+ T Cells Selectively Inhibit the Spontaneous Form of Lymphopenia-Induced Proliferation of Naive T Cells. The Journal of Immunology. 2008; 180:7305-7317.

35. Geffner L, Basile JI, Yokobori N, Sabio YGC, Musella R, Castagnino J, Sasiain MC and de la Barrera S. CD4(+) $\mathrm{CD} 25$ (high) forkhead box protein $3(+)$ regulatory $\mathrm{T}$ lymphocytes suppress interferon-gamma and CD107 expression in CD4(+) and CD8(+) T cells from tuberculous pleural effusions. Clinical and experimental immunology. 2014; 175:235-245.
36. Zhang HH, Mei MH, Fei R, Liao WJ, Wang XY, Qin LL, Wang JH, Wei L, Chen HS. Regulatory T cell depletion enhances tumor specific CD8 T-cell responses, elicited by tumor antigen NY-ESO-1b in hepatocellular carcinoma patients, in vitro. International journal of oncology. 2010; 36:841-848. 